\title{
O DISCURSO DA DISSIMULAÇÃO COMO ESPAÇO PARA CONSTRUÇÃO DO ETHOS POLÍTICO: UMA ANÁLISE DA ENTREVISTA DO PREFEITO MARCELO CRIVELLA AO SBT
}

\author{
WAGNER ALEXANDRE DOS SANTOS COSTA ${ }^{1}$ \\ MALENA RIBEIRO CARDOSO DA CONCEIÇÃO ${ }^{2}$
}

\author{
Universidade Federal Rural do Rio de Janeiro - UFRRJ \\ Instituto de Ciências Humanas e Sociais \\ Rodovia BR-465, Km 7 \\ 23897000 - Seropédica, RJ - Brasil
}

wagnercosta.prof@gmail.com, malena.ribeirocardosoclgmail.com

\begin{abstract}
Resumo. Neste artigo, estuda-se a construção do ethos político de Marcelo Crivella, prefeito da Cidade do Rio de Janeiro, em entrevista concedida à emissora SBT, em 09 de julho de 2018. A entrevista decorre de uma denúncia feita pela emissora Globo, gerando grande polemica. Crivella, em sua fala, desvia dos tópicos propostos nas perguntas da repórter e pratica a estratégia do discurso da dissimulação (CHARAUDEAU, 2006b), espaço dentro do qual constrói seu ethos de político perseguido pela sua opção religiosa. A perspectiva teórica do estudo é a da Análise Semiolinguística do Discurso (CHARAUDEAU, 2010).
\end{abstract}

Palavras-chave: Ethos; estratégia discursiva; debate politico.

\begin{abstract}
In this article, it is studied the construction of the political ethos of Marcelo Crivella, mayor of the city of Rio de Janeiro, in an interview with the broadcaster SBT, on July 9, 2018. The interview stems from a complaint made by the broadcaster Globo, creating a great controversy. Crivella, in his speech, deflects from the proposed topics questions of the reporter and practice the discourse strategy of concealment (CHARAUDEAU, 2006b), space within which he elaborates his political ethos pursued by his religious option. The theoretical perspective of this study is the semiolinguistic discourse analysis (CHARAUDEAU, 2010).
\end{abstract}

Keywords: Ethos; discursive strategy; political debate.

\footnotetext{
${ }^{1}$ Doutor em Estudos da Linguagem pela Universidade Federal Fluminense. Professor Adjunto de Língua portuguesa do Departamento de Letras e Comunicação da Universidade Federal Rural do Rio de Janeiro (DLC/UFRRJ) e do Mestrado Profissional em Letras (PROFLETRAS).

${ }^{2}$ Graduada em Letras: Português/Literaturas pela Universidade Federal Rural do Rio de Janeiro (UFRRJ). Pós-graduanda em Educação com ênfase no ciclo básico (fundamental II e ensino médio) pelo Instituto Federal de Minas Gerais - Arcos. Foi bolsista de iniciação científica (PIBIC/UFRRJ/CNPq), desenvolvendo pesquisas sobre a construção do ethos no discurso político.
} 


\section{INTRODUÇÃO}

Sexta-feira, dia 06 de julho de 2018, em tom de denúncia, o Jornal O Globo publica a reportagem intitulada Em agenda secreta com pastores, Crivella oferece cirurgias de catarata e ajuda no IPTU. Ao público, mostram-se diversos momentos em que o Prefeito da Cidade do Rio de Janeiro Marcelo Crivella (doravante, MC) oferece aos convidados, pastores de igrejas, o que a mídia jornalística e grande parte da população entenderam como vantagens exclusivas aos fiéis dos segmentos evangélicos convidados à reunião.

Outros jornais como $O$ Dia e o Estadão também apresentam suas manchetes sobre o fato, que foi discursivizado ainda em jornais e telejornais de todo o país e em vários sites de informação, nos quais vídeos e áudios da reunião são divulgados como testemunho do evento em que MC ofereceria isenção no IPTU, facilidades no atendimento a cirurgias de catarata e obras no entorno das igrejas. Rapidamente, o conteúdo da reportagem viraliza nas redes sociais sob diferentes formas de protesto, gerando intensas discussões.

Em resposta à sociedade, no dia 09 de julho de 2018, o prefeito concede uma entrevista ao programa jornalístico SBT Rio, do Sistema Brasileiro de Televisão (SBT), apresentando sua versão para o fato trazido pela reportagem. A sua fala nessa entrevista é a materialidade linguístico-discursiva a partir da qual analisamos a construção do ethos político, associando-o à categoria analítica do discurso da dissimulação. Objetiva-se compreender como essa estratégia discursiva (a dissimulação), uma categoria do estudo do discurso político (CHARAUDEAU, 2006b e 2011) pode, no contexto da entrevista, ocorrer como um espaço de construção para um ethos político elaborado por MC. ${ }^{3}$

Uma forma muito comum de operacionalizar a estratégia da dissimulação é o político responder algo diferente do que lhe foi proposto como tópico conversacional. Dessa forma, ele supostamente silencia, pelo desvio ao tema ou por fuga a uma resposta comprometedora, o desenvolvimento de uma conversa a ele desfavorável.

O contexto específico do estudo pode ser exemplificado, na entrevista, logo na primeira ocorrência de pergunta-resposta entre a jornalista do SBT Rio, Isabelle Benito (doravante, IB), e o prefeito MC:

IB: $\mathrm{O}$ senhor ofereceu a possibilidade de alguém furar a fila para o mutirão de catarata?

MC: Nunca existiu. Existe sim, por parte da Globo, que infiltrou um jornalista e que inventou que era uma reunião secreta... não é uma reunião secreta, com 170 pessoas e anunciada no WhatsApp, não tem nada de secreto nisso. Mas existe sim uma... vamos dizer assim, uma controvérsia. Todo mundo sabe, eu digo e declaro isso aqui, que a Globo é inimiga jurada dos evangélicos. A Globo é contra a família, a Globo é a favor do aborto, a Globo tem toda uma agenda que contraria os princípios cristãos, católicos e evangélicos. ${ }^{4}$

\footnotetext{
3 Entrevista acessada pela rede social da própria emissora, disponível em: https://www.facebook.com/sbtriooficial/videos/1605389706236672/?t=125. Vídeo postado no dia 9 de julho de 2018 às 14h03. Acessado em: 20 jul. 2018.

${ }^{4} \mathrm{O}$ destaque em negrito na fala do prefeito refere-se às partes que julgamos centrais para a análise do discurso da dissimulação e posterior formulação do seu ethos.
} 
No trecho apresentado, MC, por exemplo, em vez de explicar o que disse em sua fala na reunião (tópico proposto), adota o desvio do tópico como opção de resposta.

Diante do quadro exposto, consideramos a seguinte hipótese em relação ao objetivo deste estudo:

Ao dizer que a emissora Rede Globo atuaria contra valores cristãos (vide trecho acima) e, por essa razão, realizaria oposição tanto política (ao prefeito), como também religiosa (ao homem cristão), MC formularia, por decorrência, além da sua imagem, dois pares opostos entre si de imagens (ethos) de outrem:

- No primeiro par, teríamos a Globo como emissora inimiga dos evangélicos, opondo-se à imagem do SBT como emissora democrática.

- Já no segundo, a imagem dos espectadores da Globo como audiência sem adesão ao discurso evangélico, seu contradestinatário (VERÓN, 1987), versus a imagem dos espectadores do SBT como parcela não alienada da população, seu prodestinatário (VERÓN, 1987), que compartilharia com MC do seu universo de discurso.

O entrelaçamento dessas imagens pode ser pensado a partir do discurso da dissimulação, espaço estratégico no qual são desenvolvidas tais imagens. $\mathrm{MC}$, ao operar esse discurso, desviando-se do tópico proposto decorrente das perguntas, restringe sua fala a um público específico, de potencial adesão às suas ideias. Além disso, atribui à emissora Globo a discursivização intencionalmente negativa das ações políticas sobre o seu governo. Consequentemente, MC deixa entrever, pela sua vestimenta discursiva, elementos a partir dos quais se pode pensar um ethos de perseguido.

O estudo é desenvolvido principalmente pelo prisma teórico-metodológico da Análise Semiolinguística do discurso (2010), tendo-se em vista o relevo dado, no âmbito de tal teoria, aos estudos sobre o discurso político. Na próxima seção, então, será apresentado o aporte teórico basilar empregado na análise, que compreende os estudos sobre ethos discursivo, conforme Charaudeau (2011), além das estratégias discursivas no campo político, elencadas por Charaudeau (2006b e 2011).

\section{ETHOS DISCURSIVO}

O conceito de ethos, tendo sua origem na Retórica de Aristóteles, designa, de modo geral, uma imagem de si que o orador, como efeito de seu discurso, é capaz de transmitir. Não se trata de envolver propriamente as coisas que o orador poderia dizer sobre si, mas se refere, por exemplo, à maneira de o sujeito estruturar as frases, à sua seleção vocabular, a seus conhecimentos enciclopédicos demonstrados no discurso e ao seu estilo, que podem fornecer informações sobre a sua pessoa, podem "falar" por ele.

Em Retórica, Aristóteles (2005, p. 96), ao explicar que as provas de persuasão fornecidas pelo discurso são de três tipos, apresenta aquelas que residem no caráter moral do orador (ethos), de tal modo que sua credibilidade dele dependa; outras que dependem 
do modo como se dispõe o ouvinte (pathos), conforme as emoções que o orador nele possa despertar; e as que se situam no próprio discurso $(\log o s)$, em sua organização para a consecução dos seus objetivos.

Segundo ele, o caráter é o meio mais importante de persuasão:

Persuade-se pelo caráter quando o discurso é proferido de tal maneira que deixa a impressão de o orador ser digno de fé. Pois acreditamos mais e bem mais depressa em pessoas honestas, em todas as coisas em geral, mas sobretudo nas de que não há conhecimento exato e que deixam margem para dúvida. (ARISTÓTELES, 2005, p. 96)

Para obter esse ideal de persuasão, o sujeito falante precisa tomar conhecimento das ideias e dos valores do destinatário. Somente assim poderá eleger a maneira mais apropriada de se expressar, condizente com seu projeto de fala. Dessa forma, o ethos corresponderá à imagem necessária ao locutor para conquistar credibilidade junto ao seu interlocutor.

Assim, segundo Maingueneau (2005), privilegiando a visão aristotélica, a eficácia do ethos deve-se ao fato de que, sem estar explicitado no enunciado, ele envolve de alguma forma a enunciação. Trata-se da escolha das palavras, dos argumentos, do ritmo e da entonação de seu discurso.

Charaudeau (2011), por sua vez, ao abordar a problemática de o ethos ser resultado de uma construção discursiva (ethos construído) ou decorrer de uma instância prévia ao discurso (ethos pré-construído), argumenta em favor de uma visão intermediária. Segundo ele, para construir uma imagem do sujeito que fala, o interlocutor se apoia em dados apreendidos no fio do discurso, mas também se utiliza de informações sobre a pessoa, não só sobre sua configuração como enunciador. Na hipótese charaudiana, complementar à aristotélica, o ethos (prévio ou discursivo) é uma identidade independente que está vinculada a duas outras: a identidade social (lugar de legitimidade) e a identidade discursiva (lugar de credibilidade), ambas desenvolvidas no escopo da Teoria Semiolinguística (CHARAUDEAU, 2010).

O ethos no discurso político, segundo Charaudeau (2011), pode se vincular a vários ethé, que são figuras identitárias componentes de dois grandes quadros referenciais da imagem de si no campo político: ethos de credibilidade e ethos de identificação.

Esse dispositivo argumentativo que é o ethos resulta da combinação de três instâncias: duas interlocutoras e uma terceira virtual:

Toda construção do ethos se faz em uma relação triangular entre $s i$, o outro e um terceiro ausente, portador de uma imagem ideal; o outro se deixa levar por um comportamento de adesão à pessoa que a ele se dirige por intermédio dessa mesma imagem ideal de referência: o $s i$ procura endossar essa imagem ideal; o outro se deixa levar por um comportamento de adesão à pessoa que a ele se dirige por intermédio dessa mesma imagem ideal de referência (CHARAUDEAU, 2011, p. 137 , grifos do autor). 
A diferença entre o ethos de credibilidade e o de identificação é que, neste último, as imagens identitárias das quais o si lança mão para obter adesão do outro são vinculadas a uma referência afetiva fundada no próprio cidadão donde, por hipótese, surgiria o elo de identificação e se completaria a persuasão.

De modo geral, para ser "digno de fé" o sujeito deve ser capaz de conduzir o outro a crer na sua palavra, de modo que seja possível nela verificar sua: sinceridade (quando o que diz corresponde ao que pensa); performance (quando possui condições de executar aquilo que promete); e eficácia (quando o que ele anuncia e aplica é seguido de efeito). No discurso político (CHARAUDEAU, 2011), são também essas as três bases de sustentação do ethos de credibilidade, pois, para a instância política, faz-se necessário ter a fala reconhecida como verdadeira (sinceridade); ter a promessa não só feita, mas realizada, aplicada (performance); e ter condições de convencer que sua promessa pode ser cumprida e que terá resultados favoráveis (eficácia).

\section{ETHOS E ESTRATÉGIAS SEMIODISCURSIVAS NO CAMPO POLÍTICO}

Charaudeau (2006a, p. 344) particulariza a identidade social pela necessidade de ser reconhecida pelos outros. Trata-se, nos termos dessa teoria, daquilo que confere ao sujeito o direito à palavra, o que sustenta a sua legitimidade, que depende da atuação do sujeito nos domínios do saber (fundado nas opiniões, nos saberes compartilhados e no seu manuseio, com vistas à sedução e persuasão do interlocutor) e do poder (estabelecido principalmente a partir dos vínculos institucionais que conferem poder ao sujeito).

A identidade discursiva, sem se opor à anterior, apenas projetando-se num contínuo, depende não somente de o sujeito saber organizar sua fala, mas principalmente de sua capacidade em parecer digno de crédito, da necessidade de seu interlocutor considerá-lo verdadeiro. Por essa razão, a credibilidade, que depende da identidade discursiva, envolve a formulação de uma imagem de si, um ethos, sendo, pois, necessariamente estratégica.

Trata-se de uma interdependência de dois espaços reguladores do ato de comunicação: um contendo determinações sociais, outro discursivas, sendo o ethos realizado sociodiscursivamente.

Quanto ao domínio político, Charaudeau (2016, p. 73) explica que legitimidade e credibilidade estão intimamente entrelaçadas. A legitimidade conferida a um candidato pelo voto não é absoluta nem definitiva. É, pois, necessária a manutenção constante dela. Isto passa pelo exercício da credibilidade, que se faz pela linguagem.

Concebendo a atuação do político como fruto da relação entre a identidade social e a identidade discursiva, Charaudeau ressalta dois tipos de atividades determinantes. São atividades interdependentes: a primeira é a do dizer político, que se circunscreve no campo dos debates dentro do espaço público; a segunda é a do fazer político, campo mais restrito e que se refere à realização de atos, tomada de decisões (CHARAUDEAU, 2006b, p. 257). 
O sujeito político, assim, tem de construir sua palavra na interseção desses dois espaços porque seu dizer (domínio da linguagem que se estabelece por meio da luta discursiva: manipulação, promessas, ameaças etc.) deve, em tese, ser autenticado por seu fazer (ação, espaço de tensão entre as decisões da instância política e seu impacto na instância cidadã), por sua atuação, ou se circunscreverá apenas nos limites da promessa (CHARAUDEAU, 2006b, p. 257-258).

A tarefa não é simples, pois envolve a administração de mecanismos de enunciação próprios do discurso político. Verón (1987) reflete sobre essa especificidade, ao dizer que o imaginário político supõe, por hipótese, ao menos dois destinatários. O primeiro deles é o positivo, prodestinatário, que congrega das mesmas ideias, adere aos mesmos valores e persegue os mesmos objetivos, sendo seu partidário. Com este, o político estabelece uma relação enunciativa de identificação, por exemplo com o uso inclusivo do "nós" e de categorizações coletivas nas quais ele se inclui, como nos termos abaixo destacados da fala de Crivella:

Faz campanha contra os evangélicos na política, os evangélicos no palácio, os evangélicos onde for porque defende o aborto, porque é contra a família, porque prega incesto, porque prega todo tipo de coisa que tá contra os católicos e os evangélicos. (MC)

O segundo, o negativo, foi nomeado por Verón (1987) de contradestinatário e diz respeito ao conjunto de destinatários opositivos. Esses estão excluídos de uma relação de identificação, haja vista que suas crenças repousam em ideias e valores opostos ao do político. Trata-se da voz outra sempre presente como interlocução adversária. ${ }^{5}$

A atividade política, assim, por envolver uma constante tensão entre o controle do poder e a oposição a quem o detém, determina estratégias discursivas distintas. Como pontua Charaudeau (2006b, p. 258), o sujeito político pode estar em uma situação de enunciação fora da governança, quando, por exemplo, pretende conquistar um cargo político, quando disputa eleições. Pode ainda enunciar de dentro dela, caso em que ocupa algum cargo.

Assim, diversos tipos de estratégias discursivas podem ser postas em cena no campo político: a da promessa, a de decisão, a de justificação e a de dissimulação, segundo lista Charaudeau (2006b, p. 258-261), as quais alinhavamos resumidamente:

- $\quad$ Na estratégia da promessa, o político deve, simultaneamente, ser capaz de a) contemplar um ideal social de desejo/necessidade do ouvinte, mas também adequar-se às possibilidades reais de sua execução; b) obter reconhecimento, da parte dos cidadãos, como merecedor de crédito, como portador de limpas intenções e c) conseguir convencer (uso da razão) e persuadir (uso da emoção) a maioria da instância cidadã.

- A estratégia de decisão, a seu turno, está legitimada no campo da ação, e possível ao político que pode executá-la. Identifica-se uma desordem

\footnotetext{
${ }^{5}$ Não menos importante, mas no contexto deste estudo menos específica, é a figura do paradestinatário (VERÓN, 1987), que corresponde à posição dos indecisos, onde há uma suspensão de crenças positivas ou negativas em relação a ideias e valores de tal ou qual político.
} 
social, enuncia-se o dever de sua correção e revela-se a solução (a ser) adotada.

- Já a estratégia de justificação (CHARAUDEAU, 2006b e 2011) decorre da necessidade de os atores políticos se defenderem das críticas de seus opositores e da sociedade ou, às vezes, de antecipar-se a elas. As ações dos sujeitos políticos podem afetar sua legitimidade, sendo necessário recorrer a estratégias discursivas de (re)legitimação do estatuto conquistado.

- Por fim, a estratégia de dissimulação (CHARAUDEAU, 2006b e 2011) pode ser compreendida como o esforço em reduzir, pelo silêncio, a relevância de ideias que se projetam desfavoravelmente em direção ao ator político. A dissimulação é, então, uma estratégia discursiva de reação contra efeitos negativos emanados pela oposição, pela mídia ou por movimentos sociais.

\section{A ESTRATÉGIA DISCURSIVA DA DISSIMULAÇÃO NO CONTEXTO DA ENTREVISTA}

No quadro comunicacional da entrevista, tal como se configura tradicionalmente no jornalismo, há a atuação de um jornalista responsável por enunciar as perguntas ao entrevistado. Por sua vez, este deve responder, respeitando o intuito de fazer-conhecer, fazer-esclarecer, fazer-orientar, entre outros, como convém às responsabilidades do gestor público. Esse quadro, para Fávero e Andrade (1998), representaria um caso de assimetria interacional, dado que os papéis são distintos, determinados discursiva e socialmente.

No entanto, na estratégia discursiva da dissimulação, o político opera uma sobreposição de tema ao tema objeto da troca, proposto pelo entrevistador, delineando ele mesmo o que julga os operadores midiáticos deverem abordar. Esta movimentação é tratada em termos de desvio do ritual de comunicação da entrevista, uma vez que há quebra na expectativa linear de resposta ao tema proposto. Como diz Marcuschi (2003, p. 15), uma interação gera expectativas mútuas. Assim, em certos casos, como o da entrevista, é tácito que alguém que inicia uma interação o faça propondo um tema a outro, que supostamente está de acordo e o aceita.

Pode-se pôr em dúvida o comprometimento da coerência em casos de dissimulação. No entanto, ela precisa ser construída globalmente, não apenas entre um turno e outro de fala. Por exemplo, há diversas razões para a quebra de um tópico, como um fato externo à conversação, como a chegada de alguém, entre outros (MARCUSCHI, 2003, p. 81). No discurso político, uma dessas razões pode ser o uso intencional do turno de fala para o desenvolvimento de argumentos.

O esquema abaixo apresenta as duas instâncias de interlocução: o político entrevistado e o jornalista entrevistador. O tema-troca corresponde ao tópico proposto; já o tema sobreposto corresponde à fala desviante do político, representada por meio das linhas pontilhadas. 
Figura 1 - 0 discurso da dissimulação na entrevista

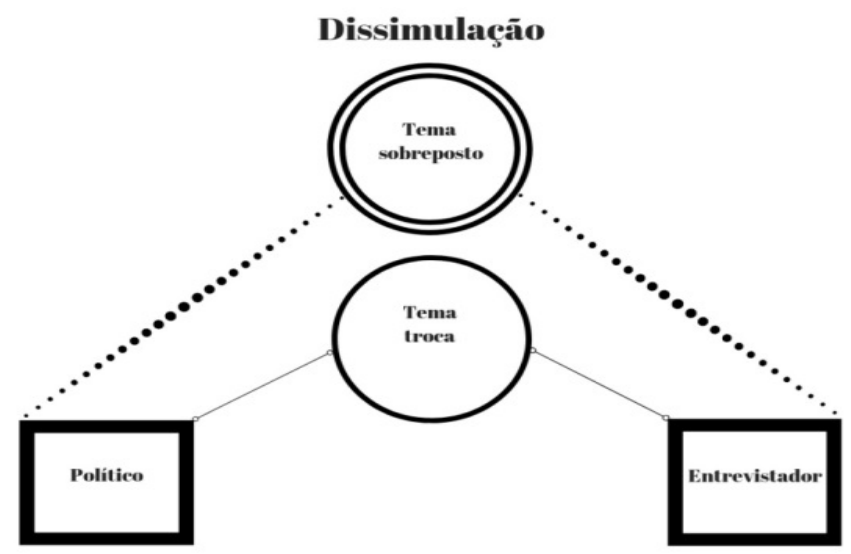

Fonte: Elaborado pelos autores

O esquema aplicado ao contexto da entrevista de MC ao SBT Rio envolve os seguintes elementos:

- Político: prefeito Marcelo Crivella (MC), responsável por responder às questões da repórter do SBT Rio, por meio do discurso da justificação, ou seja, da adoção de esclarecimentos sobre sua gestão.

- Jornalista: Isabelle Benito (IB), apresentadora do programa, dinamizadora da entrevista para a qual o prefeito foi convidado. Ela interage face a face, enunciando as perguntas enviadas por diferentes atores (público em geral, jornalista Daniel Pena Firme e professor Guilherme Carvalhido). Suas perguntas e as perguntas de outras fontes, as quais ela remete ao prefeito, instauram determinados temas a serem desenvolvidos.

- Tema-troca: corresponde àquilo que é solicitado a $\mathrm{MC}$ comentar/responder.

- Tema sobreposto: é o desvio ao tema-troca, quando o prefeito conduz seu dizer sem vínculo direto e necessário ao proposto pelo entrevistador, em outras palavras, responde o que quer.

\section{PONDERAÇÕES SOBRE A METODOLOGIA EMPREGADA}

A apreensão do ethos, ao se dar a partir da materialidade linguístico-discursiva (não propriamente nela), exige do sujeito cognoscente uma abordagem qualitativa, que é a metodologia adotada nesta análise. Isto porque se faz necessário interpretar, por meio de relações estabelecidas em diversos outros campos (social, psicológico, econômico, político e religioso, conforme a situação), a imagem que o enunciador constrói de si.

A complexidade metodológica da abordagem do conceito não se dá sem razão. Como diz Maingueneau (2011), para a elaboração do ethos interagem indícios de diversas ordens, que podem mobilizar o verbal e o não verbal. Além disso, os efeitos visados não são necessariamente os efeitos produzidos. Ainda, por se tratar de um efeito que, 
evidentemente, decorre da convergência de diversos fatores (discursivos e prédiscursivos), torna-se necessário delimitar o que priorizamos para fazer emergi-lo.

Assim, na análise que empreendemos, torne-se claro, nossa atenção recai sobre o conteúdo por meio do qual MC realiza um desvio do tópico proposto pela instância jornalística, não priorizando como objeto de suas respostas o que lhe foi perguntado.

Da fala de $\mathrm{MC}$, então, isolamos ocorrências de estratégia da dissimulação para, nesse tipo de operação discursiva, interpretar a formulação do ethos político. Ainda, destacamos em negrito, pontos acentuados da estratégia da dissimulação e construção do ethos de perseguido. Deixamos os elementos não verbais de fora da análise, uma vez que sua contribuição para o estudo da estratégia da dissimulação, neste contexto, não seria relevante. Ao ethos pré-discursivo, no entanto, recorremos constantemente, pois consideramos necessária a articulação entre o social e o discursivo (CHARAUDEAU, 2011).

\section{O DISCURSO DA DISSIMULAÇÃO NA CONSTRUÇÃO DO ETHOS NA ENTREVISTA}

Iniciamos, assim, a análise da entrevista a partir do momento em que IB, repórter do SBT, apresenta um convidado, o professor Guilherme Carvalhido, e passa a ele o turno de fala para realizar uma pergunta ao prefeito:

(1) Professor Guilherme Carvalhido: É... eu queria saber, quer dizer, diante dessa briga que o senhor tá apontando com a rede globo, né, que é uma briga política ampla, de que forma o senhor acha que isso vai repercutir na população em relação a essa sua fala? Eu entendi o que o senhor falou em relação a defesa, mas como é que o senhor acha que você vai defender essa posição em relação àqueles que viram a fala do senhor?

O professor, em (1), retoma a fala anterior de MC (entendendo-a como alusão a uma querela política com a Globo), na qual o prefeito enfatiza que a emissora é "inimiga jurada de todo o povo evangélico" (para MC, no entanto, uma querela religiosa). A pergunta incide diretamente sobre um fato: a fala de MC não só ter sido gravada pela Globo, mas também ouvida posteriormente por várias pessoas, as quais precisariam de um posicionamento do político.

Veja-se, nos trechos (2), (3), (4) e (5), a fala do prefeito. O que se pode observar, de modo recorrente nela, é a mobilização da estratégia discursiva da dissimulação, já que o político opta por conduzir seu turno de fala em direções tópicas variadas, utilizando-se de um tema sobreposto ao tema-troca. MC não apresenta quais foram as supostas distorções de sua fala nem explica que edição dela foi feita (o que seria uma possibilidade de resposta adequada à pergunta). Em vez disso, em (2), ele afirma: as pessoas que frequentam as clínicas da saúde sabem, dando início a uma série de relatos autocongratulatórios sobre a eficiência das unidades de saúde da Prefeitura.

(2) MC: Olha, Carvalhido, é simples: as pessoas que frequentam as clínicas de família da saúde sabem, todas as que têm problema de 
catarata, que a fila tá andando. Eu até arriscaria dizer pro senhor que hoje na rede pública do Rio de Janeiro, talvez seja mais rápido você fazer uma cirurgia de catarata do que se você estiver num plano de saúde privado. Nós estamos operando aos finais de semana, todos os dias fazemos terceiro turno. Aliás, não é só nas clínicas conveniadas não, também na rede pública de saúde do Rio de Janeiro, todos os dias, inclusive sábado e domingo, nós estamos fazendo o corujão carioca, operando as pessoas para diminuir a fila; de tal maneira que a população embaixo, ela vê isso estarrecida.

No trecho, o filtro com que conduz a elaboração do ethos político (dentro de um espaço estratégico da dissimulação) é o da sinceridade (CHARAUDEAU, 2011), pois intenta mostrar evidências, apresentando dados concretos, de que a dúvida posta sobre sua atuação é inverídica e, portanto, sua fala é provida de sinceridade, digna de fé. A imagem da sinceridade é reforçada por elementos subjetivos como eu arriscaria dizer pro senhor e [a população] vê isso estarrecida, que acrescentam um tom de espanto diante da acusação a que responde.

Em (3), MC novamente emprega a sobreposição ao tema-troca, retomando em sua fala a recorrente ideia do ataque costumaz da Globo aos evangélicos:

(3) MC: mas todo mundo sabe, isso é voz corrente, de que a Globo que defende um outro tipo de família, que defende o aborto, que defende $o$ incesto e coisas desse tipo, propaga isso nas suas novelas, adultério e coisas do tipo, ela é contra os princípios evangélicos, os princípios cristãos. Então, sempre que há qualquer cristão envolvido em qualquer canto do país, vai ter sempre uma visão contrária, vai ter sempre uma interpretação negativa, o que ele fizer a priori, já é considerado errado. É uma coisa de coração, é uma coisa de alma, é de índole, é de natureza, é de vocação, por isso que desde o princípio aqui no Rio de Janeiro todas as minhas ações sempre foram levadas pro lado negativo. Agora a questão eleitoral que o senhor falou, eu não vejo muito problema porque eu me elegi duas vezes senador e me elegi prefeito, eu tenho catalogado mais de mil e... em torno de mil e setecentas notícias que saíram no sistema Globo sobre a minha atuação parlamentar e depois no executivo, dá em torno de mil e setecentas. Todas elas sempre criticando, todas elas sempre com malícia, com maldade, e ganhei a eleição.

Deixa-se entrever desta visão que os programas televisivos em desacordo com a pauta cristã neopentecostal constituiriam ações contrárias aos praticantes desse segmento religioso. Tal grupo, no contexto da entrevista, confirma-se não só como grupo religioso, mas como político-religioso, pela fala própria do prefeito na qual há sua inclusão nele. ${ }^{6}$ Note-se, nesse fragmento de fala, a construção de um ethos da referida emissora, no qual é central a imagem de instituição oponente aos valores cristãos. É um ethos institucional, correspondente ao corpo coletivo profissional dos sujeitos a ela vinculados.

Por outro lado, por meio de movimentos inferenciais, que também constituem base para interpretação do ethos, compreende-se que a entrevista dada ao SBT para

\footnotetext{
${ }^{6} \mathrm{MC}$ não enunciaria na entrevista incluído apenas na categorização de prefeito. Além disso, o público evangélico do qual MC fala seria formado também por eleitores.
} 
esclarecimento do fato configura essa emissora como um espaço neutro de veiculação da verdade. Historicamente, sempre houve uma competição entre as emissoras SBT e Globo. No entanto, esta entrevista propõe um efeito visado de neutralidade em relação ao SBT, uma vez que ela (a entrevista) não poderia ocorrer na Rede Record, por esta emissora ser declaradamente do mesmo segmento evangélico praticado por MC. Então, cria-se, por meio deste sutil recurso, uma imagem do SBT como um canal de circulação da verdade, isento de qualquer viés político ou religioso e comprometido apenas com o papel do jornalismo. Noutras palavras, produz-se um efeito de verdade sobre o posicionamento dessa emissora.

Estas possibilidades de construção de ethos não podem ser interpretadas somente a partir da fala de MC. É necessário articular tanto o (ethos) prévio quanto o (ethos) discursivo (CHARAUDEAU, 2010), por exemplo, o fato de MC ter sido pastor da Igreja Universal de Reino de Deus (prévio), a relação desta com a Rede Record (prévio) e a fala do prefeito sobre a perseguição pela Globo (discursivo).

No trecho (4), MC desenvolve novamente uma fala autocongratulatória em relação à sua gestão no campo da saúde.

(4) MC: Não tive também dinheiro para colocar os 30 milhões que puseram no carnaval, mas estou tendo recursos para fazer a fila de catarata, o problema das varizes, e operando no segundo turno em toda a rede de hospital. Comprei 50 milhões de equipamentos, nove novos tomógrafos, a primeira ressonância magnética da rede pública do Rio de Janeiro, tá sendo instalada no Miguel Couto, fui eu que comprei.

Destaque-se o uso da primeira pessoa fui eu que comprei, em referência a um ato administrativo realizado com recurso financeiro público. Trata-se do desenvolvimento de um tópico não dimensionado na questão formulada pelo professor, mas que visa à construção da imagem de político eficiente.

Em (5), o prefeito retoma o conteúdo da perseguição pela Globo aos evangélicos: é uma campanha que se faz costumeiramente, não é contra mim, não, é contra os evangélicos do Brasil (MC, trecho 5).

(5) MC: Enfim, essas notícias o senhor nunca vai assistir no RJ CRIVELLA, porque no RJ CRIVELLA sempre vai ter notícias para denegrir, o prefeito é culpado de tudo, mas isso é o que eu falei para você: é uma campanha que se faz costumeiramente, não é contra mim, não, é contra os evangélicos do Brasil.

É importante considerar o destinatário dessa fala, porque também ele é alvo da construção de uma imagem, em termos mais gerais. O propósito dessa imagem consiste na identificação entre orador e auditório, pois aquele deve persuadi-lo de sua virtude, que não se configura da mesma maneira para qualquer auditório. Como lembra Maingueneau (2005), com base em Aristóteles, "é em função de seu auditório que o orador construirá uma imagem, conforme o que é considerado virtude". Ao público do SBT é, pois, atribuído um ethos conservador, capaz de compartilhar das ideias apresentadas pelo político, seu prodestinatário (VERÓN, 1987). Por outro lado, a fala de MC sobre a 
família e os valores cristãos edifica uma imagem diametralmente oposta de um ethos mundano para o espectador da Globo, ou seja, avesso aos apelos morais e religiosos, seu contradestinatário (VERÓN, 1987).

Interessante pensar que essa composição de ethos de político atacado e perseguido por sua opção religiosa, não por um ato administrativo supostamente ímprobo, possa ser eficaz conforme o auditório. Se entendermos a programação do SBT ser mais conservadora do que a da Globo, por extensão poderemos atribuir ao auditório daquela emissora também um perfil mais conservador. Dessa forma, a composição de um ethos de político perseguido por uma emissora com um perfil destoante desse auditório comportaria um discurso mais eficazmente adesivo aos seus valores. Ou seja, a referência persuasiva que funda a construção desse ethos se dá por meio da identificação com o outro (CHARAUDEAU, 2011).

São, em síntese, quatro imagens formuladas no espaço da estratégia da dissimulação: as das emissoras e as dos espectadores. Ao fazê-lo e apresentar suas ideias pela estratégia discursiva da dissimulação, MC constrói seu ethos de político perseguido, imagem compósita formada a partir de quatro outras:

\section{Figura 2 - A construção compósita do ethos de perseguido}

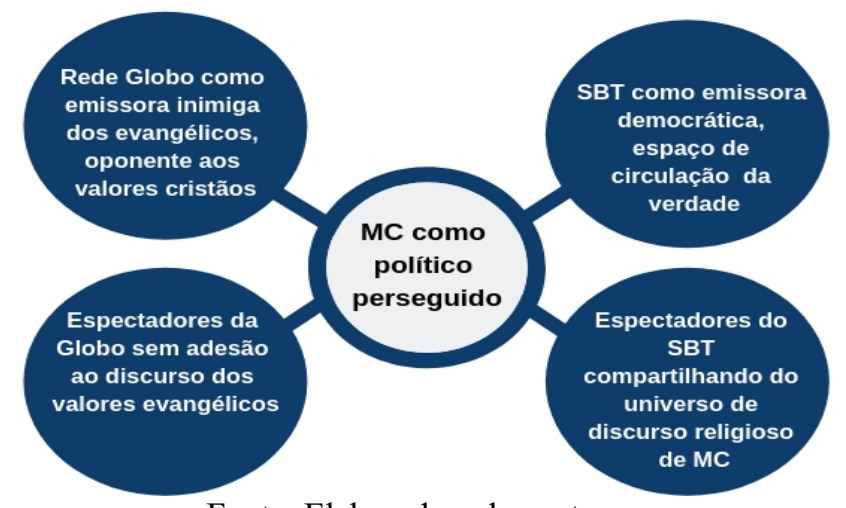

Fonte: Elaborado pelos autores

Nessa composição do ethos de político perseguido, a fala de MC incide intensamente sobre a formulação de um ethos da Globo como emissora antievangélica. As demais três imagens são interpretadas inferencialmente a partir da sua fala e da conjuntura em que a entrevista se dá.

Em outro trecho, a jornalista do SBT Rio, IB, questiona MC sobre a sua fala no áudio vazado, na qual ele recomendava que as pessoas procurassem por uma pessoa chamada Márcia:

(6) IB: Por que que o prefeito disse "Procurem a Márcia e aí a pessoa estará operando na semana que vem"? Por que a Márcia orienta como entrar na fila, seria isso, nesse sentido?

IB: Quem é a Márcia? Começa aí. 
Como resposta, MC explica que Márcia foi uma assessora sua no Senado e que agora o estaria acompanhando também na Prefeitura. Segundo ele, Márcia não colocaria pessoas na frente de outras, ela apenas as auxiliaria, indicando as medidas específicas para serem atendidas: (...) ela ajuda as pessoas a se inscreverem no SISREG, dá instruções a ele (SIC). Na conclusão de sua resposta a esta pergunta, em (7), justifica a causa da polêmica como sendo um equívoco de interpretação, arquitetado pela Globo:

(7) MC: Foi mal interpretado porque a Globo é inimiga jurada dos evangélicos, portanto, tudo o que ela puder distorcer, ela vai fazer, porque não gosta do povo evangélico e eu sou evangélico.

$\mathrm{Na}$ entrevista, nesse momento, MC diz também que Márcia entregou seu cartão a todos que estiveram presentes na reunião. No entanto, o convite não foi extensivo a toda a população da cidade, nem a ela divulgada a assessoria de Márcia. Segundo MC, foram realizados outros encontros com segmentos sociais variados no Palácio Guanabara. Quanto a essa afirmação, MC não apresentou evidências de a assessora Márcia também ter sido colocada à disposição dos demais cidadãos nos outros encontros. Isto impactou a opinião pública, pois foi entendido como um caso de privilégio a um determinado grupo.

$\mathrm{MC}$, entretanto, apresenta-se como político e religioso que sofre um tipo de oposição discriminatória liderada pela Globo. Das suas constatações, decorre que, se MC não fosse evangélico e se o encontro não fosse com pastores, não haveria qualquer tipo de polêmica. Márcia, então, poderia ter sido posta à disposição para ajudar outro grupo sem que este mesmo serviço fosse disponibilizado, ao menos publicado, para toda a população. O problema seria, assim, quanto ao grupo religioso, mas não em relação à restrição da oferta do serviço a este grupo.

Ao final da entrevista, a repórter do SBT Rio pergunta-lhe o que teria a dizer sobre a fala do representante do Ministério Público, promotor Eduardo Gussem, acerca de um possível pedido de impeachment de seu mandato de prefeito por improbidade administrativa. MC novamente opera a estratégia da dissimulação, dizendo que os indícios seriam invenções da Globo:

(8) MC: Olha, respeito muito o nosso promotor Gussem e tenho certeza que esses indícios... esses indícios, na verdade, são só fofocas da Globo, são apenas notícias fabricadas, falsas, fakes, em que pegam meus vídeos, editam, pra que as pessoas tenham uma interpretação, um entendimento errado, errôneo, os fatos não corroboram. Fico muito feliz que o Ministério Público possa, mais uma vez, tem diversas ações do Ministério Público aqui no município como em todos os municípios do Rio de Janeiro, pra investigar. Logo logo isso vai passar para o lixo da história, essa intolerância religiosa da Globo, essa perseguição, ser inimiga jurada dos evangélicos em todos os eventos, não importa... aonde tem um evangélico, a Globo tá lá para falar mal, pra denegrir, pra interpretar erroneamente a priori qualquer ação que ele faça.

No trecho (8), responde à pergunta da repórter avaliando as supostas provas como fofocas, como elementos falsos, criados contra ele pela Globo. Atribui toda a questão política enfrentada a uma causa de discriminação religiosa: o fato de ser evangélico, que seria motivo para ter sua imagem denegrida pela emissora. 


\section{CONCLUSÃO}

A análise da entrevista concedida por Marcello Crivella ao SBT Rio revela, a partir de sua fala associada a dados pregressos ao evento comunicativo sob tela, a construção de um ethos político que não se alicerça centralmente sobre qualidades tradicionalmente almejadas pelo ator público, como a eficiência e a honestidade.

A situação específica da entrevista em resposta à acusação de concessão de privilégios a grupos de um segmento religioso evangélico edifica um ethos de perseguição sofrida pelo prefeito. É a partir dessa imagem que ele nega as acusações, forjando um espaço que the permite sequer considerar a necessidade de operar o discurso da justificação, aquele tradicionalmente realizado pelo político quando precisa oferecer uma explicação sobre sua atuação pública.

O recurso estratégico adotado por Marcelo Crivella foi, assim, o de se esquivar das respostas às perguntas que lhes seriam potencialmente embaraçosas ou para as quais talvez não tivesse respostas plausíveis. Então, o político se utiliza intensamente do discurso da dissimulação, tal como descrito por Charaudeau (2006b e 2011), para a construção de um espaço dentro do qual pudesse desenvolver tópicos que apoiassem sua imagem.

Para construção da imagem de si, um ethos de político perseguido, injustiçado por sua opção religiosa, injustiçado por ser evangélico, Crivella formula quatro outras imagens. As duas primeiras são as das emissoras: a da Globo como inimiga dos evangélicos e, por consequência, inimiga política do prefeito e a do SBT, como neutra política e religiosamente, portanto lugar qualificado para a veiculação da verdade.

As duas outras são as imagens dos espectadores. Por procedimentos tanto sociais quanto discursivos, assim aliando o quadro externo da linguagem ao seu discursivo e interno (CHARAUDEAU, 2010), consideramos ainda as imagens do espectador da Globo como aquele isento dos valores ético-morais e cristãos, público que respaldaria o discurso da emissora Globo contra a família, por exemplo, pela aderência a pautas progressistas (contradestinatário). Já o público para o qual discursava, o do SBT, sobre ele Crivella constrói uma imagem mais conservadora, potencialmente aderente ao seu universo de discurso, a de um público possivelmente atento aos valores cristãos (prodestinatário). A esse respeito, bem lembra Maingueneau (2005) que a persuasão depende de o auditório identificar no orador um mesmo ethos que o seu, por isso o político aposta em produzir sobre seu público a impressão de ser um dos seus. A fala de Crivella apoia-se, então, em efeitos persuasivos supostos, mas de alguma forma alicerçados nos valores desse grupo.

Enfim, a elaboração de um ethos de político perseguido não pode ser construída em qualquer espaço, ela requer, também estrategicamente, de um onde que especifique e concentre o auditório alvo do discurso.

Por fim, entendemos que o uso do discurso da dissimulação e a formulação desse ethos foi um recurso encontrado para a obtenção de um espaço no qual Crivella pudesse obter a adesão de seu auditório. Ele, então, não precisaria desenvolver argumentos lógicos 
afinados aos tópicos propostos e esclarecer a polêmica criada. Poderia, diferentemente, mobilizar diante do seu público uma imagem que por si defenderia seus atos.

\section{REFERÊNCIAS}

ARISTÓTELES. Retórica. Lisboa: Imprensa Nacional-Casa da Moeda, 2005.

CHARAUDEAU, P. Identité sociale et identité discursive, le fondement de la compétence communicationnelle. Gragoatá, n. 21, p. 339-354, jul./dez. 2006. Niterói: EdUFF, 2006a. CHARAUDEAU, P. O discurso político. In: EMEDIATO, W; MACHADO, I.L; MENEZES, W (Orgs.). Análise do discurso: gêneros, comunicação e sociedade. Programa de Pós-graduação em Estudos linguísticos. Faculdade de Letras da UFMG, 2006b.

CHARAUDEAU, P. Linguagem e discurso: modos de organização. São Paulo: Contexto, 2010.

CHARAUDEAU, P. Discurso político. São Paulo: Contexto, 2011.

CHARAUDEAU, P. A conquista da opinião pública: como o discurso manipula as escolhas políticas. São Paulo: Contexto, 2016.

FÁVERO, L.L.; ANDRADE, M.L.C.V.O. Os processos de representação da imagem pública nas entrevistas In: PRETI, Dino. Estudos de língua falada. São Paulo: Humanitas, 1998, vol. 3, p. 153-177.

KERBRAT-ORECCHIONI, Catherine. Système linguistique et ethos communicatif. Cahiers de praxématique, n. 38, 2002, p. 35-57.

MAINGUENEAU, D. Ethos, cenografia, incorporação. In: AMOSSY, R. Imagens de si no discurso: a construção do ethos. São Paulo: Contexto, 2005, p. 69-92.

MAINGUENEAU, D. A propósito do ethos. In: MOTTA, Ana Raquel; SALGADO, Luciana (Orgs.). Ethos discursivo. São Paulo: Contexto, 2011.

MARCUSCHI, L. Análise da conversação. São Paulo: Ática, 2003.

VERÓN, E. La palabra adversativa - Observaciones sobre la enunciación politica. In: VERÓN, E. Discurso político, lenguaje y acontecimientos. Buenos Aires: Hachette, 1987, p. 13-26.

Artigo recebido em: abr. de 2020.

Aprovado e revisado em: out. de 2020.

Publicado em: dez. de 2020.

Para citar este texto:

COSTA, Wagner Alexandre dos Santos; CONCEIÇÃO, Malena Ribeiro Cardoso da. O Discurso da Dissimulação como Espaço para Construção do Ethos Político: uma análise da entrevista do prefeito Marcelo Crivella ao SBT. Entremeios [Revista de Estudos do Discurso, ISSN 21793514, on-line, www.entremeios.inf.br], Seção Estudos, Programa de Pós-Graduação em Ciências da Linguagem (PPGCL), Universidade do Vale do Sapucaí (UNIVÁS), Pouso Alegre (MG), vol. 22, p. 17-31, jul. - dez. 2020.

DOI: http://dx.doi.org/10.20337/ISSN2179-3514revistaENTREMEIOSvol22pagina17a31 